\title{
The use of pediatric flexible bronchoscopy in the COVID-19 pandemic era
}

\author{
Domenico Paolo La Regina MD ${ }^{1}$ | Raffaella Nenna PhD ${ }^{1}$ | Dirk Schramm MD ${ }^{2}$ (1) | \\ Nadine Freitag $\mathrm{MD}^{2}$ | Pierre Goussard $\mathrm{PhD}^{3}{ }^{\infty}$ | Ernst Eber $\mathrm{MD}^{4}$ (i) | \\ Fabio Midulla $\mathrm{PhD}^{1}$
}

${ }^{1}$ Department of Maternal Infantile and Urological Sciences, Sapienza University of Rome, Rome, Italy

${ }^{2}$ Department of General Pediatrics, Neonatology, and Pediatric Cardiology, University Children's Hospital Duesseldorf, Duesseldorf, Germany

${ }^{3}$ Department of Pediatrics and Child Health, Faculty of Medicine and Health Sciences, Tygerberg Hospital, Stellenbosch University, Cape Town, South Africa

${ }^{4}$ Division of Pediatric Pulmonology and Allergology, Department of Pediatrics and Adolescent Medicine, Medical University of Graz, Graz, Austria

\section{Correspondence}

Fabio Midulla, MD, PhD, Department of Maternal Infantile and Urological Sciences, Sapienza University of Rome, Viale Regina Elena 324, 00161 Rome, Italy.

Email: midulla@uniroma1.it

\begin{abstract}
On March 11, 2020, the World Health Organization (WHO) declared the pandemic because of a novel coronavirus, called severe acute respiratory syndrome coronavirus 2 (SARS-CoV-2). In January 2020, the first transmission to healthcare workers (HCWs) was described. SARS-CoV-2 is transmitted between people because of contact, droplets, and airborne. Airborne transmission is caused by aerosols that remain infectious when suspended in air over long distances and time. In the clinical setting, airborne transmission may occur during aerosol generating procedures like flexible bronchoscopy. To date, although the role of children in the transmission of SARS-CoV-2 is not clear the execution of bronchoscopy is associated with a considerably increased risk of SARS-CoV-2 transmission to HCWs. The aim of this overview is to summarize available recommendations and to apply them to pediatric bronchoscopy. We performed systematic literature searches using the MEDLINE (accessed via PubMed) and Scopus databases. We reviewed major recommendations and position statements published at the moment by the American Association for Bronchology and Interventional Pulmonology, WHO, European Center for Disease Prevention and Control and expert groups on the management of patients with COVID-19 to limit transmission among HCWs. To date there is a lack of recommendations for safe bronchoscopy during the pandemic period. The main indications concern adults and little has been said about children. We have summarized available recommendations and we have applied them to pediatric bronchoscopy.
\end{abstract}

\section{KEYWORDS}

children, COVID-19, flexible Bronchoscopy, healthcare workers, SARS-CoV-2

\section{1 | INTRODUCTION}

On January 9, 2020, the Chinese Center for Disease Control and Prevention reported that a novel coronavirus had been detected. ${ }^{1}$ Since then the virus has spread all over the world, and on March 11, 2020 the World Health Organization (WHO) declared the pandemic. ${ }^{2}$ Until May
27, 2020, the worldwide number of confirmed coronavirus disease (COVID)-19 cases had reached 5,488,825 with 349,095 deaths. ${ }^{3}$ In this context, children are less affected and have a milder symptomatology, even if currently we do not know the reason. ${ }^{4}$

In January 2020, the first transmission to healthcare workers (HCWs) was described and the first reported fatality related to 
severe acute respiratory syndrome coronavirus 2 (SARS-CoV-2) infection was an otolaryngologist from Wuhan, China. ${ }^{5}$ As of April 8, 2020, a total of 22,073 COVID-19 cases among HCWs from 52 countries have been reported to the $\mathrm{WHO},{ }^{6}$ but this number probably under-estimates the true number of SARS-CoV-2 HCW infections globally because to date there has been no systematic reporting of HCW SARS-CoV-2 infections to the WHO. While $\mathrm{HCW}$ represent less than $3 \%$ of the population in the large majority of countries, around 14\% of COVID-19 cases reported to WHO are among HCWs. In some countries, the proportion can be as high as $35 \%$. However, high quality data are limited, and it is not possible to establish whether HCWs were infected in the workplace or in community settings. Some reviews present more precise data, as in the case of China and Italy. ${ }^{7}$ In these countries, HCWs represent about $10 \%$ of reported cases. ${ }^{8,9}$ It is likely that nosocomial outbreaks play an important role in amplifying local outbreaks. For this reason, correct management in the hospital environment among HCWs is essential.

Airborne transmission is caused by aerosols that remain infectious when suspended in air over long distances and time. In the clinical setting, airborne transmission may occur during aerosol generating procedures (AGPs) like bronchoscopy (other AGPs are tracheal intubation, noninvasive ventilation (NIV), tracheotomy, manual ventilation before intubation). ${ }^{10}$ To date, although the role of children in the transmission of SARS-CoV-2 is not clear, the execution of bronchoscopy is associated with a considerably increased risk of SARS-CoV-2 transmission to HCWs caused by both close contact with the child during the procedure and the possibility of aerosol generation. $^{12,13}$

During the COVID-19 pandemic, the American Association for Bronchology and Interventional Pulmonology (AABIP), WHO, European Center for Disease Prevention and Control (ECDC) and expert groups have offered recommendations and position statements on the management of patients with COVID-19 to limit transmission among HCWs during various procedures, including bronchoscopy. ${ }^{11,14-18}$

With the current lack of recommendations for pediatric bronchoscopy the aim of this overview is to summarize available recommendations and to apply them to pediatric bronchoscopy.

\section{2 | METHODS}

We performed systematic literature searches using the MEDLINE (accessed via PubMed) and Scopus databases, searching for relevant terms related to "COVID-19" or "SARS-CoV-2" and one of the following: "children," "transmission," "healthcare workers," "aerosol generating procedures," "bronchoscopy" published until December 2020. We have analyzed the situation reports and interim guidance of WHO, ECDC technical reports, Institute of Health data, major recommendations and position statements published by the AABIP and expert groups on the management of patients with COVID-19 to limit transmission among HCWs.
Except one Italian report of Higher Institute of Health, all articles analyzed are in English language.

\section{I SARS-COV-2 INFECTION: GENERAL INFORMATIONS}

\subsection{SARS-CoV-2 infection: differences between children and adults}

The first confirmed pediatric case of SARS-CoV-2 infection was reported in Shenzhen on January 20. ${ }^{19}$ Epidemiological studies suggest that children comprise only $1 \%-2 \%$ of all SARS-CoV-2 cases. ${ }^{20,21}$ Some studies have suggested that children are as likely as adults to become infected with SARS-CoV- $2,{ }^{22}$ though more recent studies have reported that children are less likely to get infected after contact with a SARS-CoV-2 positive person. ${ }^{23-25}$ In particular, it has been suggested that children and adolescents have similar viral loads and may therefore be as likely to transmit SARS-CoV-2 as adults. ${ }^{26,27}$ Moreover, viral load seems to be similar between asymptomatic and symptomatic individuals. ${ }^{28,29}$

According to available data, compared with adults, children infected with SARS-CoV-2 have milder disease that occurs after 1-14 days of incubation (median: 5-6 days). Fever and cough are the most common clinical manifestations, sometimes accompanied by fatigue, myalgia, nasal congestion, runny nose, sneezing, sore throat, headache, dizziness, vomiting, and abdominal pain. ${ }^{30-33} \mathrm{~A}$ minority of children with COVID-19 require hospitalization, however, younger children are vulnerable to the disease and may experience severe outcomes, ${ }^{34}$ but the risk of death is very low. The percentage of asymptomatic infected children is about $4 \%-15 \% .^{32,35-37}$

To date, there are many theories about why children are less involved and have milder symptoms compared to adults. These include (1) differences density, affinity and distribution of ACE-2 receptors compared to adults; (2) trained immunity; and (3) preexisting immunity to endemic coronaviruses. In addition, factors that put adults at higher risk compared to children are: (1) a higher prevalence of comorbidities; (2) an age-related increase in endothelial damage and changes in clotting function; (3) lower levels of vitamin D; (4) immunosenescence and inflammaging., ${ }^{4,38}$

\section{2 | Transmission of SARS-CoV-2}

Based on current evidence, SARS-CoV-2 is transmitted between people via droplets, aerosols and contact (including both direct, indirect and close contact like contact for more than $15 \mathrm{~min}$ and less than one meter of distance). Aerosols and droplets are expelled when a person coughs, sneezes, talks or sings. ${ }^{39,40}$ The large particles $(>5-10 \mu \mathrm{m})$, called droplets, remain airborne only briefly before settling because of gravity. Speech and breathing also produce smaller and much more numerous particles $(<5 \mu \mathrm{m})$, known as aerosol particles. These particles are carried by air currents and 
dispersed by diffusion and air turbulence. Inhaled droplets and aerosol particles have different sites of deposition in the respiratory system. Inhaled aerosolized particles can penetrate to the depths of the lungs depositing in the alveoli, whereas inhaled droplets are deposited in the upper respiratory tract. ${ }^{41}$ Aerosols from infected persons may therefore pose an inhalation threat even at considerable distances and in enclosed spaces, particularly if there is poor ventilation. For this reason, it is important to ensure adequate ventilation of enclosed spaces where such persons are known to be or may recently have been and wear a suitable mask whenever it is thought that infected persons may be nearby.

\section{3 | Risk of transmission of SARS-Cov-2 infection to healthcare workers and AGPs}

AGPs may expose HCWs to pathogens causing acute respiratory infections, but the risk of transmission of acute respiratory infections through AGPs is not fully known. Guidelines generally consider as AGPs such as intubation, preintubation ventilation, bronchoscopy, tracheotomy, open airway suctioning, cardiopulmonary resuscitation, $\mathrm{NIV}$, nebulizer treatment, administration of $\mathrm{O}_{2}$, high flow $\mathrm{O}_{2}$, manipulation of $\mathrm{O}_{2}$ mask or BiPAP mask, insertion of a nasogastric tube and collection of sputum. Some reviews report a higher risk of transmission for tracheal intubation followed by NIV, tracheotomy and manual ventilation before intubation. ${ }^{10,42}$ These reviews showed that bronchoscopy is a procedure with an increased risk, but confidence intervals were wide. A study on influenza A H1N1 reported an increased detection of viral aerosols following bronchoscopy and airway suctioning. ${ }^{43}$ Also, bacteria have been detected in ambient air after bronchoscopy, but HCW transmission was not studied. ${ }^{44}$ Considering the very small number of studies and the inconsistent and imprecise results, more stringent measures should be taken to prevent the spread of SARS-Cov- 2 to HCWs. ${ }^{45}$

\section{4 | GENERAL MEASURES}

\subsection{Admission to hospital}

Health institutions or health personnel should educate the patients' parents to inform HCWs if their children have respiratory symptoms (or other symptoms attributable to SARS-CoV-2 infection like fever, fatigue, myalgia, headache, dizziness, vomiting, abdominal pain, etc.) or if they had a close contact with an infected person by calling ahead of time or whenever they arrive at the hospital. In fact, asymptomatic SARS-CoV-2 infection, also in children, poses a risk to staff undertaking AGPs, with potential for unexpected transmission of SARS-CoV-2 to HCWs because a very high viral load has been detected in the airways of infected patients with SARS-CoV-2 infection. ${ }^{46}$

Moreover, health institutions should educate the patients to wear a facemask, if available, during transport and at screening in the hospital, ${ }^{47}$ wash hands at hospital entrance with soap and water or alcohol-based hand rub and maintain social distance by staying at least one meter away, whenever possible, from anyone.

To facilitate the early identification of suspected cases, healthcare facilities should:

- encourage HCWs to have a high level of clinical suspicion;

- establish a well-equipped screening station at the entrance to the facility, supported by trained staff;

- institute the use of screening questionnaires according to the updated case definition. ${ }^{48}$

Clinical screening includes a system for assessing all patients at admission, allowing to stratify patients and to recognize possible SARS-CoV-2 infection early. This allows immediate isolation of patients with suspected infection in an area separate from other patients to prevent transmission to HCWs and other patients. A recommended, rapid screening system to be performed at screening is called "FTOCC": (1) Fever higher than $37.5^{\circ} \mathrm{C}$ or other symptoms attributable to SARS-CoV-2 infection; (2) Travel history; (3) Occupational exposure; (4) Contact history; and (5) Clustering. ${ }^{49}$

Other symptoms attributable to SARS-CoV-2 infection are cough, fatigue, myalgia, nasal congestion, runny nose, sneezing, sore throat, headache, dizziness, vomiting, and abdominal pain.

Occupational exposure, not in reference to children but to parents, should take into account parents working as HCWs and research laboratory staff handling SARS-CoV-2 samples.

Contact history should trace those who have had recent close contact with COVID-19 patients in the last 14 days.

Clustering represents two or more SARS-CoV-2 positive patients with a history of close contact. Any of the positive criteria for FTOCC should be regarded as indicating a clinically suspected case.

\section{2 | Screening to stratify patients: suspect, probable, and confirmed or negative for SARS-CoV-2}

Case definitions are based on currently available information and are regularly revised as new information accumulates. Countries may need to adapt case definitions depending on their local epidemiological situation and other factors. ${ }^{50}$

- Suspected case:

A patient with acute respiratory illness (fever and at least one sign/symptom of respiratory disease, e.g., cough or shortness of breath), and one of following three items:

(1) A history of travel or residence in a location reporting community transmission of SARS-CoV-2 during the 14 days before symptom onset;

(2) Contact with a confirmed or probable COVID-19 case in the last 14 days before symptom onset; 
(3) Absence of an alternative diagnosis that fully explains the clinical presentation and requiring hospitalization;

- Probable case:

A suspected case for whom testing for SARS-CoV-2 is inconclusive or a suspected case for whom testing could not be performed for any reason.

- Confirmed case:

A person with laboratory confirmation of SARS-CoV-2 infection, irrespective of clinical signs and symptoms.

One or more negative results do not rule out the possibility of SARS-CoV-2 infection. Some reviews reported negative predictive values of PCR tests; values were between $65 \%$ and above $90 \% .{ }^{51-53}$

If a negative result is obtained from a patient with a high index of suspicion for SARS-CoV-2 infection, particularly when only upper respiratory tract specimens were collected, additional specimens from the lower respiratory tract should be considered, for example, by bronchoscopy. ${ }^{54}$

\section{3 | Personal protective equipment (PPE) selection}

Protection of our frontline HCWs is paramount and PPE-including medical masks, gloves, gowns, and eye protection must be prioritized for HCWs and others caring for COVID-19 patients. In view of the global PPE shortage, strategies that can facilitate optimal PPE availability include minimizing the need for PPE in healthcare settings, ensuring rational and appropriate use of PPE, and coordinating PPE supply chain management mechanisms. Recommendations for PPE in patient rooms/wards are as follows:

(1). For HCWs with direct contact to COVID-19 patients, in the absence of AGPs, the following items are required: medical mask (consider respirator N95 or FFP2 or FFP3 standard if available), gown, gloves, eye protection (goggles or face shield).

(2). For HCWs with direct contact to COVID-19 patients, in settings where AGPs are frequently in place, the following items are required: respirator N95 or FFP2 or FFP3 standard, or equivalent, gown, gloves, eye protection and apron.

\section{5 | SPECIFIC MEASURES FOR PEDIATRIC FLEXIBLE BRONCHOSCOPY}

\subsection{Postpone non urgent cases}

Bronchoscopy is used to explore the airways, to obtain biological samples and for treatment purposes ${ }^{55-57}$ (e.g., foreign body extraction, removal or reduction of an endobronchial tumor, insertion of a stent). Indications for bronchoscopy differ between children and adults. In the pandemic it would be useful to differentiate three categories of pediatric bronchoscopies: urgent, semi-urgent, and elective (Table 1).
TABLE 1 Main indications for pediatric bronchoscopies according to categories

\begin{tabular}{|ll}
\hline Categories & Indications \\
\hline $\begin{array}{l}\text { Urgent bronchoscopy } \\
\text { (essential bronchoscopy) }\end{array}$ & $\begin{array}{l}\text { 1. Severe airways obstruction } \\
\text { 2. Foreign body inhalation }\end{array}$ \\
$\begin{array}{ll}\text { 3. Massive hemoptysis } \\
\text { (nemi-urgent bronchoscopy } \\
\text { by case) } & \text { 1. Respiratory samples collection for } \\
& \text { 2. Removal of mucus plugs in } \\
\text { Elective bronchoscopy } & \text { 1. Bronchioctasis } \\
\text { (deferred until further } & \text { 2. Chest X-ray anomalies } \\
\text { notice) } & \text { 3. Chronic cough } \\
& \text { 4. Evaluation of artificial airways } \\
& \text { 5. Recurrent pneumonia }\end{array}$ \\
\hline
\end{tabular}

Abbreviations: HCW, healthcare worker; SARS-CoV-2, severe acute respiratory syndrome coronavirus 2 .

${ }^{a}$ Collection of bronchoalveolar lavage fluid should be done with care and only if it will benefit the patient as it may increase the risk of droplet spread for HCWs.

${ }^{\mathrm{b}}$ Bronchoscopy has a limited role in the diagnosis of SARS-CoV-2 infection and should only be considered in intubated patients if upper respiratory samples are negative. ${ }^{13}$ If bronchoscopy is performed in such instances, a minimum of $2-3 \mathrm{ml}$ of specimen into a sterile, leak proof container for specimen collection is recommended. ${ }^{59}$

All airway endoscopies are generating aerosol and are therefore considered high risk procedures for pathogen transmission to $\mathrm{HCWs} .{ }^{10}$ For this reason, all patients should be screened for SARS-Cov-2 infection. In urgent settings we suggest the rapid molecular test, for which less variation compared with rapid antigen tests, and an average sensitivity of $95.2 \%$ (95\% confidence interval [Cl]: $86.7 \%-98.3 \%$ ) and specificity of $98.9 \%$ (95\% Cl: $97.3 \%-99.5 \%)$ have been shown. ${ }^{53}$

In patients with suspected or confirmed SARS-CoV-2 infection, bronchoscopy is relatively contraindicated. However, urgent bronchoscopy may need to be done without results of SARS-CoV-2 testing available, like in the middle of the pandemic. Bronchoscopy should only be considered in cases of urgent life-saving interventions, when suspicion of an alternative diagnosis would impact clinical management or when less invasive testing to confirm SARS-CoV-2 infection is inconclusive. Urgent bronchoscopy must be performed as soon as possible and in any case within $24 \mathrm{~h}$ after emergency department admission. Elective bronchoscopies should be postponed until after full recovery and after the patient has been declared free of infection with negative PCR testing and without symptoms. ${ }^{13}$ There is consensus with this policy, preventing potential transmission of SARS-CoV-2 between patients and HCWs, which has been advocated by various groups. ${ }^{13-17,46,47,60,61}$

\section{2 | Prebronchoscopy}

In communities with a high prevalence of SARS-CoV-2 infections, proper isolation precautions should always be applied, using a room 
with negative pressure settings or a designated airborne infection isolation room (AIIR). This also applies for routine flexible bronchoscopies in asymptomatic patients.

All patients with indications for bronchoscopy will be required to wear surgical masks, perform hand hygiene with alcohol-based hand rub and/or wear gloves. Patients should avoid close contact in the bronchoscopy unit maintaining a distance of at least $1 \mathrm{~m}$ or, if possible, each patient should be in a single room until the bronchoscopy is performed. The number of patients in waiting areas should be restricted and the number of staff should be kept to a minimum in bronchoscopy units. Caregivers or parents must also wear masks as they may be a bigger risk to HCWs than the child.

All HCWs working in a bronchoscopy unit should receive appropriate education and training in infection control measures, including hand hygiene and the use of PPE. ${ }^{61}$

Since the mode of transmission is primarily usually unknown, the WHO recommends that when a novel Acute Respiratory Disease is identified, the highest available level of infection control precautions should be implemented until the situation and mode of transmission is clarified. ${ }^{11}$ For this reason, at the beginning of the epidemic, health authorities recommended a higher level of protection than the current one, similar to that used for previous epidemics such as by Ebola virus. ${ }^{62}$ To date, some hospitals continue to use increased protection measures compared to those declared by health authorities.

According to health authorities all HCWs who perform bronchoscopies in suspected or confirmed COVID-19 cases should wear the following enhanced PPE: an N95 mask (FFP2 or FFP3 mask), eye protection with lateral protection (goggles or face shield), a waterproof long-sleeved gown, an apron and one pair of non-sterile gloves (double gloving is not recommended except for surgical procedures that carry a high risk of rupture) (Figure 1). ${ }^{14,63}$ Canadian anesthesiologists advise to consider the use of powered air purifying respirators (PAPRs) for high-risk procedures. ${ }^{64}$ However, PAPRs are expensive and not available in all, especially resource limited, countries. For this reason many hospitals have had to procure alternatives to traditional PPE, like the use of a full face diving mask adapted with filters for use during bronchoscopy. ${ }^{65}$

The following paragraph summarizes the recommended steps for donning PPE.

1. Identify and gather the proper PPE to don.

2. Perform hand hygiene by rubbing them with an alcohol-based formulation as the preferred means for routine hygienic hand antisepsis if hands are not visibly soiled. Wash your hands with soap and water when hands are visibly dirty or visibly soiled with blood or other body fluids or after using the toilet.

3. Put on an isolation gown. Tie all of the ties on the gown. Assistance may be needed by another HCW.

4. Put on an N95 filtering facepiece respirator or higher (use a facemask if a respirator is not available). Respirator/facemask should be extended under the chin. Both mouth and nose should be protected.
5. Put on a face shield or goggles (face shields may be safe to use, but they distort the view, which is problematic during interventional bronchoscopy. Consider use of modified diving masks since they work very well in this setting ${ }^{65}$ ).

6. Perform hand hygiene before putting on gloves. Gloves should cover the cuff (wrist) of the gown.

Staff's exposure time should be reduced by permitting patient and caregiver to enter the bronchoscopy theater only after all preparations are complete. ${ }^{65}$ To reduce HCWs' exposure only essential people should be present during induction, bronchoscopy and when waking up the patient.

\section{3 | Bronchoscopy}

Bronchoscopy should be performed in an adequately ventilated room with air flow of at least $160 \mathrm{~L} / \mathrm{s}$ per patient or in negative pressure rooms with at least 12 air changes per hour. ${ }^{66}$

Although studies on high-efficacy particulate air (HEPA) filtration of SARS-CoV-2 are yet to be published and the Centers for Disease Control and Prevention has not yet provided any recommendations for the use of portable air purifiers, HEPA filters have been shown to be effective and their efficacy in capturing and containing particles is well documented. HEPA filters are composed of mats of randomly arranged fibers that intercept passing particles by a combination of diffusion, interception, and inertial impaction. This provides their filtration capacity which is effective to $99.97 \%$ of 0.1 micron particles. ${ }^{67}$ Thus, we can consider them as an adjunctive means for decontamination of SARS-CoV-2 aerosols in clinical areas or procedure rooms. ${ }^{68-70}$

The Chinese Thoracic Society has provided specific precautions: to reduce cough and sputum, patients should be properly sedated before bronchoscopy (e.g., with muscle relaxants). In our opinion, this precaution can be applied only in patients without significant airway obstruction. Alfentanil $10 \mu \mathrm{g} / \mathrm{kg}$ should be used to obtund airway reflexes and the response to a possible placement of an endotracheal tube or a laryngeal mask airway (LMA). ${ }^{65}$ Spontaneous breathing should be utilized to reduce aerosol generation.

Patients under local anesthesia and without intubation should wear masks to cover their mouths. To clear the coughed droplets of a patient it is possible to use a suction tube in the mouth (Figure 2).

For patients undergoing NIV, a NIV mask with a bronchoscope inlet to perform bronchoscopy through the inlet can be used, avoiding ventilation or oxygen administration during the examination (Figure 3). Alternatively, a three-way connector allowing to insert the bronchoscope through the suction hole (Figure 4A) or a double swivel elbow adapter with suction port may be used. In intubated patients the bronchoscope can be inserted through a port used to suction reducing the risk of aerosol efflux (Figure 4B). ${ }^{71}$

In patients with an LMA, a Rusch Mainz Universal Adapter should be placed between the anesthetic breathing circuit and the LMA to ensure a sealed channel for both bronchoscopy and 


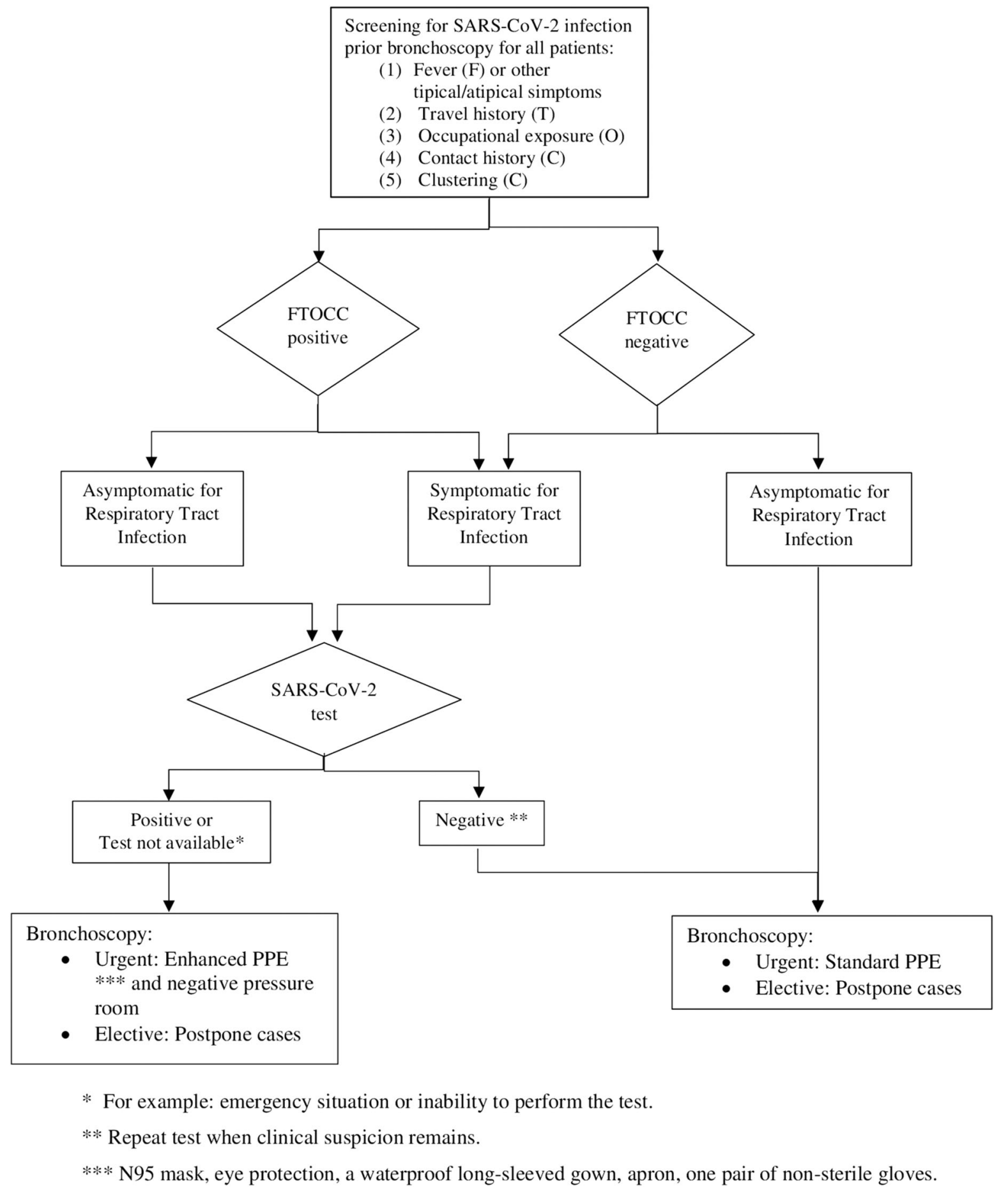

FIGURE 1 Flow chart for bronchoscopy during the COVID-19 pandemic

ventilation while minimizing the risk for aerosolization. An LMA should be removed under deep sevoflurane anesthesia to reduce aerosol production through coughing. ${ }^{65}$

During the COVID-19 pandemic, flexible bronchoscopy is preferable to rigid bronchoscopy (in some instances, foreign bodies can also be removed with flexible bronchoscopes). Flexible bronchoscopy should be performed first in SARS-CoV-2 positive individuals or in unknown cases, to determine if rigid bronchoscopy is indicated; the latter should be avoided if possible, due to the increased risk of droplet spread. $^{72}$

\section{4 | Postbronchoscopy}

After bronchoscopy, correct doffing of PPE is very important to limit spread of infection. This procedure should be performed in an 


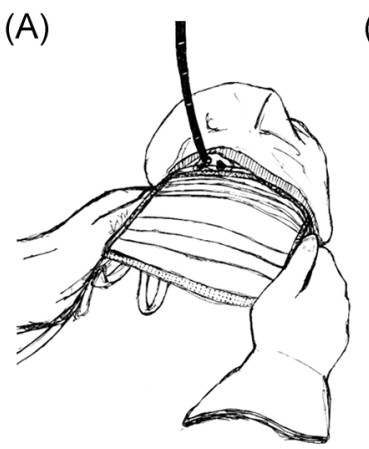

(B)

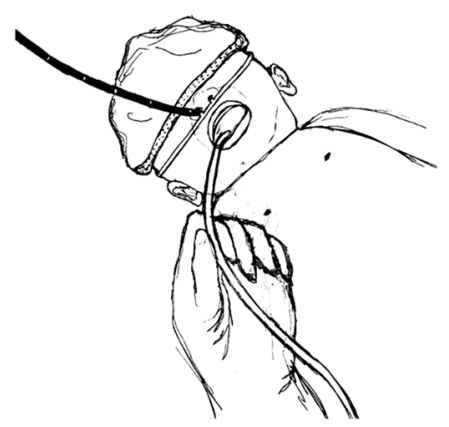

FIGURE 2 Prevention of patient's aerosol transmission during bronchoscopy, with surgery mask (A) and suction (B). Illustrations by D.P. La Regina

appropriate PPE doffing room. The following paragraph summarizes recommended steps for doffing of PPE.

1. Remove gloves. Ensure glove removal does not cause additional contamination of hands.

2. Remove gown. Untie all ties (or unsnap all buttons). Reach up to the shoulders and carefully pull gown down and away from the body. Rolling the gown down is an acceptable approach. Dispose in trash receptacle.

3. Perform hand hygiene.

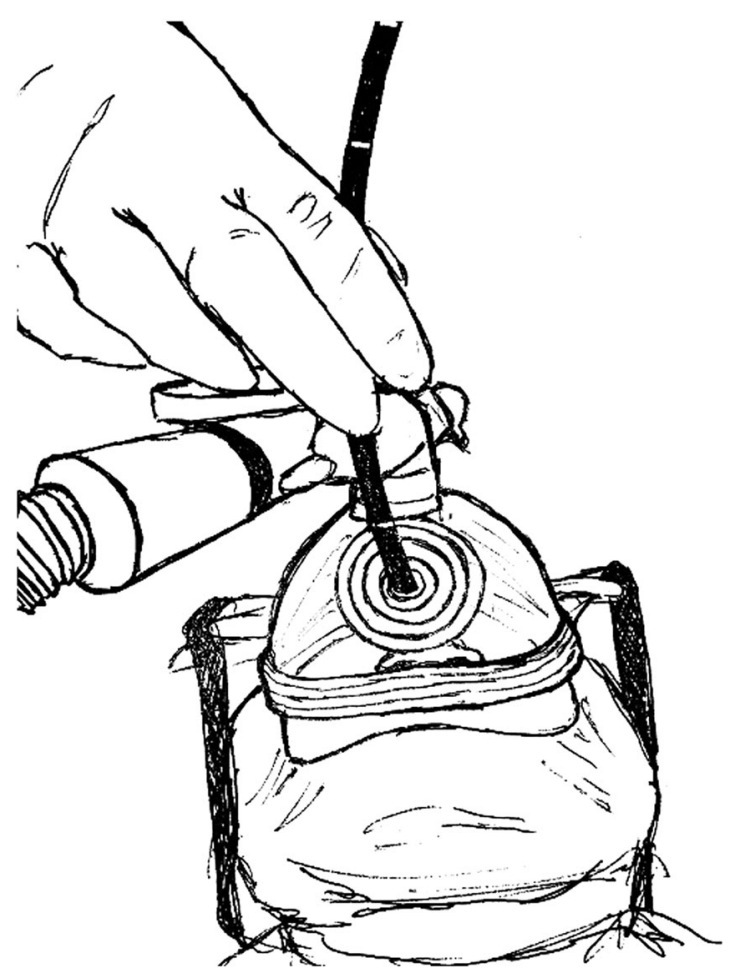

FIGURE 3 Noninvasive ventilation mask with bronchoscope insertion channel. Illustrations by D.P. La Regina
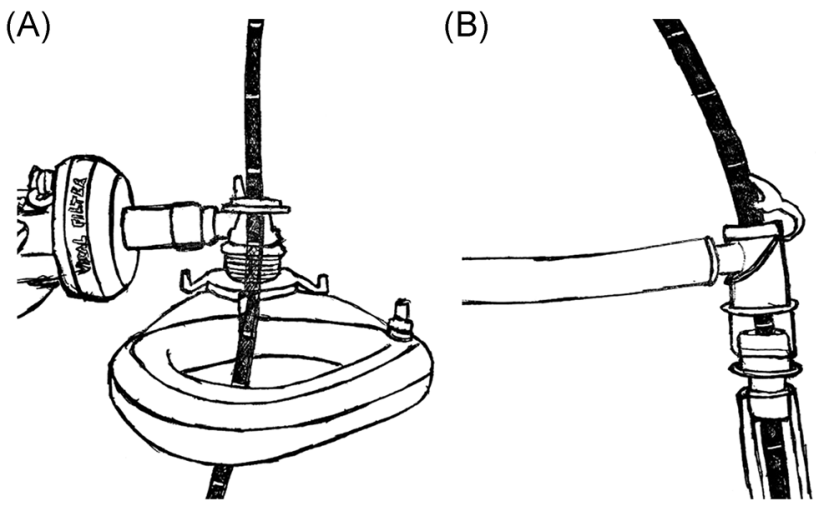

FIGURE 4 Bronchoscope inserted through a suction port of a three-way connector of a noninvasive ventilation mask (A), and bronchoscope inserted through a suction port of a three-way connector of an extension tube (B). Illustrations by D.P. La Regina

4. Remove face shield or goggles. Carefully remove face shield or goggles by grabbing the strap and pulling upwards and away from head. Do not touch the front of face shield or goggles.

5. Remove and discard respirator (or facemask if used instead of respirator). Do not touch the front of the respirator or facemask.

6. Perform hand hygiene after removing the respirator/facemask and before putting it on again if your workplace is practicing reuse.

The reuse of masks, gowns, or eye protection is strongly discouraged. The removal, storage, redonning, and reuse of the same, potentially contaminated PPE items without adequate reprocessing is one of the principal sources of risk to HCWs. ${ }^{15}$ It could be useful to wear a surgical mask covering an FFP2 mask. In such way, the outer surgical mask can be discarded, and operators keep the FFP2 mask, avoiding to lose their face protection.

Microorganisms have been detected on the walls of endoscopy suites and postoperative recovery areas. ${ }^{56}$ After the bronchoscopy is finished, the bronchoscope should be inserted into a $75 \%$ alcohol bottle for negative pressure suction to clean and sterilize the suction tube of the bronchoscope. At the same time, wipe the surface of the bronchoscope with $75 \%$ alcohol, and then send to sterilization after sealing the bronchoscope with a sealed bag. Glutaraldehyde can be used to sterilize the flexible bronchoscope by leaving it immersed for $20 \mathrm{~min}$. Then rinse and dry well.

On plastic and steel, SARS-CoV-2 remains infectious for more than $80 \mathrm{~h}^{73}$ Aerosol and fomite transmission of SARS-CoV-2 is plausible, since the virus can remain viable and infectious in aerosols for hours and on surfaces up to days (depending on the inoculum shed). Bronchoscopy theaters must be clean and surfaces washed off. Personnel should be careful with notes and reports, trying to keep the theater paperless. Finally, all tools close to the patient should be disinfected after each examination (e.g., monitor, light source).

If appropriate, patients can be transported with masks directly to the ward and not to the recovery room to lessen exposure of more HCWs. 


\section{5 | Follow-up}

If possible, it is preferable to contact patients by phone to inquire about their health and any new diagnoses or the development of COVID-19 associated symptoms. If the latter are present, healthcare professionals who have been in contact with the patient must be identified and health surveillance must be activated.

\section{6 | CONCLUSIONS AND FUTURE CONSIDERATIONS}

This article aims to summarize and discuss available evidence for pediatric bronchoscopy, providing indications to avoid nosocomial outbreaks and to enhance safety of healthcare personnel, ensuring rational use of PPE. With the steady increase in the number of confirmed cases of COVID-19 in different countries and cities worldwide, it is difficult to determine the most appropriate time to resume regular service at bronchoscopy centers. The resumption of a bronchoscopy service will depend on the following factors: (1) the number and epidemic curve of confirmed COVID-19 cases; (2) the availability of medical equipment, including appropriate PPE; and (3) the accumulated volume of postponed bronchoscopy cases.

\section{AUTHOR CONTRIBUTIONS}

Domenico Paolo La Regina: conceptualization (equal); investigation (equal); writing original draft (equal). Raffaella Nenna: investigation (equal); methodology (equal); writing original draft (equal). Dirk Schramm: writing review \& editing (equal). Nadine Freitag: writing review \& editing (equal). Pierre Goussard: writing review \& editing (equal). Ernst Eber: writing review \& editing (equal). Fabio Midulla: supervision (lead); validation (lead).

\section{DATA AVAILABILITY STATEMENT}

The data that support the findings of this study are available from the corresponding author upon reasonable request.

\section{ORCID}

Dirk Schramm (D) http://orcid.org/0000-0002-0440-4737

Pierre Goussard (D) http://orcid.org/0000-0003-1146-1307

Ernst Eber (D) https://orcid.org/0000-0001-7628-030X

Fabio Midulla (D) http://orcid.org/0000-0001-8880-3462

\section{REFERENCES}

1. World Health Organization. Coronavirus disease (COVID-2019) situation reports. situation report - 1, 2020. Available from: https:// www.who.int/docs/default-source/coronaviruse/situation-reports/ 20200121-sitrep-1-2019-ncov.pdf?sfvrsn=20a99c10_4

2. World Health Organization. Director-General's opening remarks at the media briefing on COVID-19 - 11 March 2020. Available from: https://www.who.int/dg/speeches/detail/who-director-general-sopening-remarks-at-the-media-briefing-on-covid-19-11-march2020
3. World Health Organization. Coronavirus disease (COVID-2019) situation reports. situation report - 128, 2020. Available from: https://www.who.int/docs/default-source/coronaviruse/situationreports/20200527-covid-19-sitrep-128.pdf?sfvrsn=11720c0a_2

4. Cristiani L, Mancino E, Matera L, et al. Will children reveal their secret? The coronavirus dilemma. Eur Respir J. 2020;55:2000749.

5. Chan JYK, Wong EWY, Lam W. Practical aspects of otolaryngologic clinical services during the 2019 novel coronavirus epidemic: an experience in Hong Kong. JAMA Otolaryngol Head Neck Surg. 2020; 146(6):519-520.

6. World Health Organization. Coronavirus disease (COVID-2019) situation reports. situation report - 82, 2020. Available from: https:// www.who.int/docs/default-source/coronaviruse/situation-reports/2 0200411-sitrep-82-covid-19.pdf?sfvrsn=74a5d15_2

7. World Health Organization. Keep health workers safe to keep patients safe. Available from: https://www.who.int/news/item/17-092020-keep-health-workers-safe-to-keep-patients-safe-who

8. World Health Organization. Report of the WHO-China Joint Mission on Coronavirus Disease 2019 (COVID-19). Geneva: WHO; 2020. Available from: https://www.who.int/docs/defaultsource/coronaviruse/who-china-joint-missionon-covid-19-finalreport.pdf

9. Istituto superiore di sanità. Sorveglianza integrata COVID-19 in Italia: Aggiornamento 09 Aprile 2020. Rome: Istituto superiore di sanità; 2020. Available from: https://www.epicentro.iss.it/coronavirus/ bollettino/Bollettino-sorveglianza-integrata-COVID-19_9-aprile2020.pdf

10. Tran K, Cimon K, Severn M, Pessoa-Silva CL, Conly J. Aerosol generating procedures and risk of transmission of acute respiratory infections to healthcare workers: a systematic review. PLoS One. 2012;7(4):e35797.

11. World Health Organization. Infection prevention and control of epidemic and pandemic prone acute respiratory infections in health care WHO Guidelines. Available from: https://apps.who.int/iris/bitstream/ handle/10665/112656/9789241507134_eng.pdf?sequence=1\%26is Allowed $=y$

12. Li X, Xu W, Dozier M, He Y, Kirolos A, Theodoratou E. UNCOVER The role of children in transmission of SARS-CoV-2: a rapid review. J Glob Health. 2020;10(1):011101.

13. Diercks GR, Park BJ, Myers LB, Kwolek CJ. Asymptomatic COVID-19 infection in a child with nasal foreign body. Int J Pediatr Otorhinolaryngol. 2020;135:110092.

14. Wahidi MM, Lamb Carla, et al. American Association for Bronchology and Interventional Pulmonology (AABIP) Statement on the Use of Bronchoscopy and Respiratory Specimen Collection in Patients with Suspected or Confirmed COVID-19 Infection. J Bronchology Interv Pulmonol, 2020;27(4):e52-e54.

15. World Health Organization. Rational use of personal protective equipment for coronavirus disease (COVID-19) and considerations during severe shortages. Interim guidance. 6 April 2020.

16. European Center for Disease Prevention and Control. Technical report. Contact tracing: public health management of persons, including healthcare workers, having had contact with COVID-19 cases in the European Union - second update. 8 April 2020. Available from: https://www.ecdc.europa.eu/sites/default/files/ documents/Contact-tracing-Public-health-management-personsincluding-healthcare-workers-having-had-contact-with-COVID-19cases-in-the-European-Union\%E2\%80\%93second-update_0.pdf

17. Ferioli M, Cisternino C, Leo V, Pisani L, Palange P, Nava S. Protecting healthcare workers from SARS-CoV-2 infection: practical indications. Eur Respir Rev. 2020;29:200068.

18. Flick H, Arns BM, Bolitschek J, et al. Management of patients with SARS-CoV-2 infections and of patients with chronic lung diseases during the COVID-19 pandemic (as of 9 May 2020). Wien Klin Wochenschr. 2020;132:365-386. 
19. Chan JFW, Yuan S, Kok KH, et al. A familial cluster of pneumonia associated with the 2019 novel coronavirus indicating person-toperson transmission: a study of a family cluster. Lancet. 2020;395: 514-523.

20. Wu Z, McGoogan JM. Characteristics of and important lessons from the coronavirus disease 2019 (COVID-19) outbreak in China: summary of a report of 72314 cases from the chinese center for disease control and prevention. JAMA. 2020;323:1239-1242.

21. Parri N, Lenge M, Buonsenso D. Children with Covid-19 in pediatric emergency departments in Italy. N Engl J Med Overseas Ed. 2020; 383:187-190.

22. Bi Q, Wu Y, Mei S, et al. Epidemiology and transmission of COVID-19 in 391 cases and 1286 of their close contacts in Shenzhen, China: a retrospective cohort study. Lancet Infect Dis. 2020;20:911-919.

23. Mizumoto $\mathrm{K}$, Omori $\mathrm{R}$, Nishiura $\mathrm{H}$. Age specificity of cases and attack rate of novel coronavirus disease (COVID-19). medRxiv. 2020. https://doi.org/10.1101/2020.03.09.20033142

24. Milani GP, Bottino I, Rocchi A, et al. Frequency of children vs adults carrying severe acute respiratory syndrome coronavirus 2 asymptomatically. JAMA Pediatr. 2020;175:193. https://doi.org/10.1001/ jamapediatrics.2020.3595

25. Viner RM, Mytton OT, Bonell C, et al. Susceptibility to SARS-CoV-2 infection among children and adolescents compared with adults: a systematic review and metaanalysis. JAMA Pediatr. 2020;175:143. https://doi.org/10.1001/jamapediatrics.2020.4573

26. Baggio S, L'Huillier AG, Yerly S, et al. SARS-CoV-2 viral load in the upper respiratory tract of children and adults with early acute COVID-19. Clin Infect Dis. 2020. https://doi.org/10.1093/cid/ ciaa1157

27. L'Huillier AG, Torriani G, Pigny F, Kaiser L, Eckerle I. CultureCompetent SARS-CoV-2 in nasopharynx of symptomatic neonates, children, and adolescents. Emerg Infect Dis. 2020;26:2494-2497.

28. Hurst JH, Heston SM, Chambers HN, et al. SARS-CoV-2 infections among children in the biospecimens from respiratory virus-exposed kids (brave kids) study. medRxiv. 2020. https://doi.org/10.1101/ 2020.08.18.20166835

29. Lee S, Kim T, Lee E, et al. Clinical course and molecular viral shedding among asymptomatic and symptomatic patients with SARS-CoV-2 infection in a community treatment center in the Republic of Korea. JAMA Intern Med. 2020;180:e203862.

30. She J, Liu L, Liu W. COVID-19 epidemic: disease characteristics in children. J Med Virol. 2020;92(7):747-754. https://doi.org/10.1002/ jmv. 25807

31. Tezer H, Bedir Demirdağ T. Novel coronavirus disease (COVID-19) in children. Turk J Med Sci. 2020;50(SI-1):592-603.

32. Dolores De Luca C, Esposito E, Cristiani L, et al. Covid-19 in children: a brief overview after three months experience. Paediatr Respir Rev. 2020;35:9-14.

33. Ludvigsson JF. Systematic review of COVID-19 in children shows milder cases and a better prognosis than adults. Acta Paediatr. 2020; 109(6):1088-1095. https://doi.org/10.1111/apa.15270

34. Stower $\mathrm{H}$. Clinical and epidemiological characteristics of children with COVID-19. Nat Med. 2020;26:465.

35. Yasuhara J, Kuno T, Takagi H, Sumitomo N. Clinical characteristics of COVID-19 in children: a systematic review. Pediatr Pulmonol. 2020;55(10):2565-2575.

36. Dong $\mathrm{Y}, \mathrm{Mo} \mathrm{X}, \mathrm{Hu} \mathrm{Y}$, et al. Epidemiology of COVID-19 among children in China. Pediatrics. 2020;145(6):e20200702.

37. Cruz AT, Zeichner SL. COVID-19 in Children: initial characterization of the pediatric disease. Pediatrics. 2020;145(6):e20200834.

38. Zimmermann P, Curtis N. Why is COVID-19 less severe in children? A review of the proposed mechanisms underlying the age-related difference in severity of SARS-CoV-2 infections. Arch Dis Child. 2020. http://doi.org/10.1136/archdischild-2020-320338
39. World Health Organization (WHO). Transmission of SARS-CoV-2: implications for infection prevention precautions. Available from: https://www.who.int/news-room/commentaries/detail/transmissionof-sars-cov-2-implications-for-infection-prevention-precautions

40. Anfinrud P, Stadnytskyi V, Bax CE, Bax A. Visualizing speechgenerated oral fluid droplets with laser light scattering. N Engl J Med. 2020;382(21):2061-2063.

41. Meselson M. Droplets and aerosols in the transmission of SARS-CoV-2. N Engl J Med. 2020;382(21):2063.

42. Bronchoscopy, laryngoscopy, and esophagoscopy during the COVID-19 pandemic. Head Neck. 2020;42(7):1634-1637.

43. Thompson K-A, Pappachan Jv, Bennett AM, et al. Influenza Aerosols in UK Hospitals during the H1N1 (2009) pandemic-the risk of aerosol generation during medical procedures. PLoS One. 2013;8:e56278.

44. Marchand G, Duchaine C, Lavoie J, Veillette M, Cloutier Y. Bacteria emitted in ambient air during bronchoscopy-a risk to health care workers? Am J Infect Control. 2016;44:1634-1638.

45. Harding H, Broom A, Broom J. Aerosol-generating procedures and infective risk to healthcare workers from SARS-CoV-2: the limits of the evidence. J Hosp Infect. 2020;105(4):717-725.

46. Zou L, Ruan F, Huang M, et al. SARS-CoV-2 viral load in upper respiratory specimens of infected patients. N Engl J Med. 2020; 382(1177):1179.

47. Centers for Disease Control and Prevention. Triage of Suspected COIVD-19 Patients in non-US Healthcare Settings. Available from: https://www.cdc.gov/coronavirus/2019-ncov/hcp/non-us-settings/ sop-triage-prevent-transmission.html

48. World Health Organization. Infection prevention and control during health care when COVID-19 is suspected. Interim guidance 19 March 2020.

49. Wong ATY, Chen H, Liu S, et al. From SARS to avian influenza preparedness in Hong Kong. Clin Infect Dis. 2017;64:S98-S104.

50. World Health Organization. Global surveillance for COVID-19 caused by human infection with COVID-19 virus. Interim guidance 20 March 2020.

51. Stites EC, Wilen CB, The Interpretation of SARS-CoV-2 Diagnostic Tests, Med, Volume 1, Issue 1, 2020, Pages 78-89, ISSN 2666-6340.

52. George B, McGee J, Giangrasso E, Finkelstein S, Wu S, Glatt AE. What Is the predictive value of a single nasopharyngeal SARS-CoV-2 PCR swab test in a patient with COVID-like symptoms and/or significant COVID-19 exposure? Open Forum Infect Dis. 2020;7(10): ofaa399.

53. Dinnes J, Deeks JJ, Adriano A, et al.; Cochrane COVID-19 Diagnostic Test Accuracy Group Rapid, point-of-care antigen and molecular-based tests for diagnosis of SARS-CoV-2 infection. Cochrane Database Syst Rev. 2020;8:CD013705.

54. World Health Organization. Laboratory testing for coronavirus disease (COVID-19) in suspected human cases. Interim guidance 19 March 2020.

55. Eber E, Antón-Pacheco JL, de Blic J, et al. ERS statement: interventional bronchoscopy in children. Eur Respir J. 2017;50:1700901.

56. Wallis C, Alexopoulou E, Antón-Pacheco JL, et al. ERS Statement on Tracheomalacia and Bronchomalacia in Children. Eur Respir J. 2019; 54(3):1900382.

57. Schramm D, Yu Y, Wiemers A, et al. Pediatric flexible and rigid bronchoscopy in European centers-Availability and current practice. Pediatr Pulmonol. 2017;52(11):1502-1508. https://doi.org/10.1002/ ppul.23823

58. Johnston ER, Habib- Bein N, Dueker JM, et al. Risk of bacterial exposure to the endoscopist's face during endoscopy. Gastrointest Endosc. 2019;89:818-824.

59. World Health Organization. Laboratory testing for 2019 novel Coronavirus (2019-nCov) in suspected human cases. Interim Guidance 17 Jan 2020. 
60. $\mathrm{Ng} \mathrm{K}$, Poon BH, Kiat Puar TH, et al. COVID-19 and the risk to health care workers: a case report. Ann Intern Med. 2020;172:766-767.

61. Chiu PWY, Ng SC, Inoue H, et al. Practice of endoscopy during COVID-19 pandemic: position statements of the Asian Pacific Society for Digestive Endoscopy (APSDE- COVID statements. https://doi.org/10.1136/gutjnl-2020-321185

62. Joseph T, Moslehi MA. COVID-19 E-Book "International pulmonologist's consensus on covid-19" 2nd Edition 2020; 8: 30-34

63. European Centre for Disease Prevention and Control. Personal protective equipment (PPE) needs in healthcare settings for the care of patients with suspected or confirmed 2019-nCoV. Stockholm, ECDC, 2020.

64. Wax RS, Christian MD. Practical recommendations for critical care and anesthesiology teams caring for novel coronavirus (2019-nCoV) patients. Can J Anaesth. 2020;67:568-576.

65. Goussard P, Van Wyk L, Burke J, et al. Bronchoscopy in children with COVID-19: a case series. Pediatr Pulmonol. 2020;55: 2816-2822.

66. World Health Organization. Clinical management of severe acute respiratory infection (SARI) when Covid-19 disease is suspected. Interim guidance. Avaible from: https://apps.who.int/iris/handle/ 10665/331446? show=full

67. Schentag JJ, Akers C, Campagna P, Chirayath P. SARS: clearing the air. Washington (DC). National Academies Press; 2004.

68. Rebmann T. Management of patients infected with airborne-spread diseases: an algorithm for infection control professionals. Am J Infect Contr. 2005;33:571e9-579e9.

69. Christopherson DA, Yao WC, Lu M, Vijayakumar R, Sedaghat AR. High-efficiency particulate air filters in the era of COVID-19: function and efficacy. Otolaryngol Head Neck Surg. 2020;163(6): 1153-1155.

70. Centers for Disease Control and Prevention. Considerations for optimizing the supply of powered air-purifying respirators (PAPRs): for healthcare practitioners (HCP). Published April 19, 2020. Accessed May 22, 2020. Avaible on https://www.cdc.gov/coronavirus/ 2019-ncov/hcp/ppe-strategy/powered-air-purifying-respiratorsstrategy.html

71. Respiratory Care Committee of Chinese Thoracic Society. Expert consensus on preventing nosocomial transmission during respiratory care for critically III patients infected by 2019 novel coronavirus pneumonia. ZhonghuaJie He He Hu Xi Za Zhi. 2020;17:EO20.

72. Francom CR, Javia LR, Wolter NE, et al. Pediatric laryngoscopy and bronchoscopy during the COVID-19 pandemic: a four-center collaborative protocol to improve safety with perioperative management strategies and creation of a surgical tent with disposable drapes. Int J Pediatr Otorhinolaryngol. 2020;134:110059.

73. Van Doremalen N, Bushmaker T, Morris DH, et al. Aerosol and surface stability of SARS-CoV-2 as compared with SARS-CoV-1. N Engl J Med. 2020;382(16):1564-1567.

How to cite this article: La Regina DP, Nenna R, Schramm D, et al. The use of pediatric flexible bronchoscopy in the COVID-19 pandemic era. Pediatric Pulmonology. 2021;1-10. https://doi.org/10.1002/ppul.25358 